\title{
Challenges in Romanian technical higher education from the perspective of the european requirements for its modernization
}

\author{
Felicia Veronica Banciu $^{1, *}$, Eugen Pămîntaș ${ }^{1}$ \\ ${ }^{1}$ Politehnica University Timisoara, Faculty of Mechanics, Materials and Manufacturing Engineering Dep., Bd. Mihai Viteazu No 1, \\ 300222, Timișoara, Romania
}

\begin{abstract}
In today's economically changing environment, higher education institutions faces many challenges regarding permanent adaptations to industry needs, inappropriate financing arrangements, the knowledge triangle of teaching, research and innovation, tailored approaches to learning for students, students centred education, reforms in the education system etc. The problem mentioned in European agenda for higher education modernization linked to the inconsistency between the knowledge and skills graduates gain from the educational process and those required by the economy and society remains one major problem, at least at this moment. In regard to this, the paper aim is to analyses the actual situation regarding the consequences of an admission without exam where the baccalaureate grade is taken into account, and as possible solutions to this major challenge are emphasised possible training methods appropriate to the presented situation, methods with a great emphasis on the practical side and the permanent emphasis of the theoretical background used. In this context, good anticipation and thoroughly prepared restructuring is needed, attention and unified efforts from specialists in education field, industry and whole higher education system in order to face actual situation and be prepared for challenges that this problems will rise in the future.
\end{abstract}

\section{Introduction}

In November 2011, European Union (EU) member ministers, worried about the growing gap with the advanced Asian states but especially with the United States, analysed the current situation, identified major shortcomings and established the Agenda for Higher Education Systems Modernization in Europe.

Among the objectives, priority was "to improve the quality and relevance of higher education, so that the curriculum corresponds to the needs of the students, employers and careers of the future, as well as the increase in the number of graduates" [1], one of the main objectives of the Europe 2020 strategy being that by 2020 , $40 \%$ of young people should graduate a higher education institution or equivalent studies.

The European Commission, aware of the Agenda objectives, in order not to remain only a noticed activity, adopts a support strategy that will be granted to the modernization of higher education in the Member States and according to it, immediately in September 2012, the Commissioner for Education, Culture, Multilingualism and European union youth at that time, Androulla Vassilioiu, constitutes a high-level group for the modernization of higher education, chaired by former Irish President Mary McAleese. In the first report of the aforementioned working group, published on 18.06.2013, 16 recommendations are formulated, of which, on the subject of this article, we mention:

- introduction of compulsory certified vocational training for teachers and other teachers in higher education; - focusing activities on student support in developing entrepreneurial and innovative skills;

- the creation of a European Academy for teaching and learning. In order to analyse what has been done and what needs to be done to achieve the Education\&Training 2020 objectives in terms of higher education, a new agenda for the modernization of higher education systems in Europe [2] was drafted on 30.05.2017.

\section{Findings and recommendations of public consultation at European level on the modernization of higher education}

This agenda is based on a series of preliminary public consultation of which can be extracted several aspects / specific recommendations which are related to the topic of this paper [3]:

- globalization and digitization directly affects higher education institutions and the economic environment, society ( $30 \%$ of today's occupations did not exist 20 years ago). Routine jobs can be replaced by advanced technologies.

- the problem of the inconsistency between the knowledge and skills graduates gain from the educational process and those required by the economy and society; - graduates work on positions where they cannot fully use their high-level skills;

\footnotetext{
* Corresponding author: felicia.banciu@upt.ro
} 
- people designing higher education courses are insufficiently aware of potential skills needs in the labor market;

- broadening access to higher education - through tailored approaches to learning and better student support and guidance mechanisms;

- that technology was not yet used effectively to improve teaching and learning (the way blended learning is used); - the challenge that the training of researchers of the future raises;

- inappropriate financing arrangements - especially for countries in central and eastern Europe;

-the growing importance of a range of "transversal", skills, such as critical thinking, problem-solving or communication;

- skills gaps encompass the broad fields of Science Technology, Engineering and Math, where many national authorities and stakeholders see a need to strengthen highlevel skills provision;

Attempts to help students acquire the right knowledge and skills:

-importance of increasing the diversity (and quality) of higher education programmes, to be able to respond to diverse student needs and diverse demand for skills;

-support teachers and reward good teaching in higher education; training available to teaching staff in higher educations should be improved;

-increasing the links between higher education and other economic actors, including through involvement in the design and delivery of programs and the provision of work-based learning opportunities;

- Internationalisation and mobility help students acquire skills needed for an internationalised world;

- a broader conception of innovation that should include both an entrepreneurial mind-set (as well as a creative mind-set with a long-term focus on seeking sustainable solutions across the disciplinary boundaries;

-strengthening the knowledge triangle of teaching, research and innovation was a key priority for fostering the innovative potential of students and higher education institutions;

- high quality doctoral training to ensure high quality academic research and to support high quality teaching and effective cooperation activities in higher education and deliver the top-level experts needed in other parts of the economy and society outside academia.

Romania, despite the fact that it is making progress on the Europe 2020 [4,5] targets on employment rates, national greenhouse gas emissions, renewable energy, energy efficiency and tertiary education mentions limited progress quality mass education, research and development intensity, and also early school leaving remain some distance away from their respective targets, labour and skills supply are not keeping up with the fastchanging needs of the economy and maybe one of the most important is linked to the weak performance of the education system limits growth prospects in the long run.

Each country through its government and ministries is responsible for organizing and delivering higher education while EU actions provide a general framework and guidelines for studies, teaching and research activities, or policy-making in the field, all together seen in the dimension of the European international space. Reforms in education are medium and long term, with impact and results that take time to be observable, analysed and eventually made changes to them to meet society's demands.

Given the numerous attempts to reform the education system, and especially considering the numerous toplevel changes at the level of the ministry that governs education in Romania, one can ask whether the recommendations of the European Commission (EC) Working Group have also taken into account the Romanian realities and are they suitable for this case.

This paper seeks to analyse the state of the Romanian higher education so that it can respond appropriately and reasonably to the above question.

\section{Romanian Technical Education in the face to of European requirements}

According to a study based on the European Union Labor Force Survey, Romania has a progressive increase with regard to the population aged between 30-34 years and graduating a higher education institution (International Standard Classification of Education ISCED 5-8) (in 2001-2005 period), from $13.9 \%$ in 2007 to $26.3 \%$ in 2017 , thus being near its target of $26.7 \%$ (Fig.1). [6]

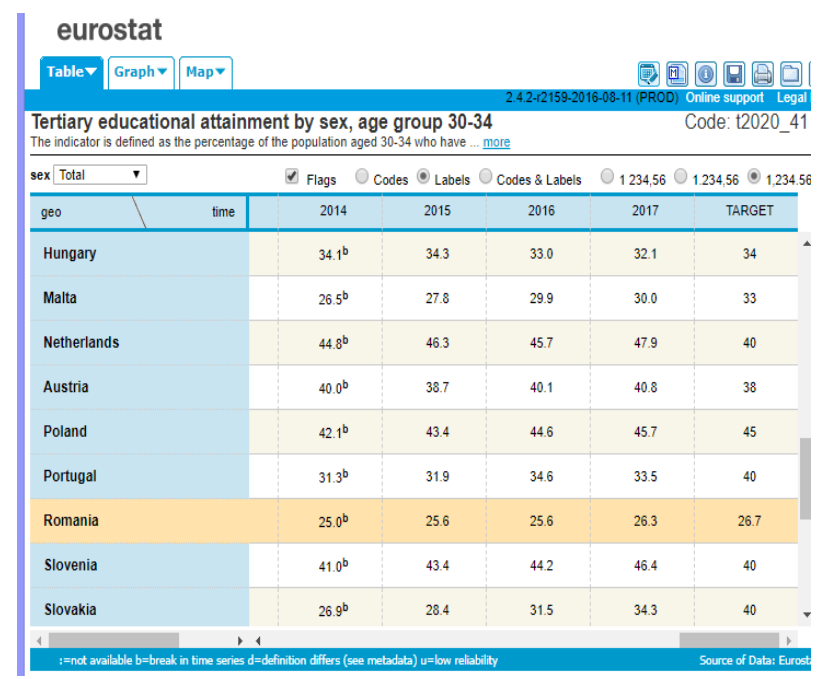

Fig 1. .Tertiary educational attainment by sex, age, group 30-34 [6]

Although Romania is close to the 2020 target for higher education graduates [8], the number of high school baccalaureate graduates is decreasing and the rate of advancement is below $70 \%$ (66.7 in $2016,68.1 \%$ in 2017) [7] (Figure 2). It should not be forgotten that in 2004, the baccalaureate graduation was higher than $80 \%$ after the first session.

At the same time, compared to the level of students training in the years 2001-2005, the training level of those who accede in higher education in the last years is lower, at least at some specializations. For example, in the school year 2017/2018, at industrial engineering admitted students in year I, $62 \%$ have baccalaureate averages lower 
than 7 (in the case where the minimum grade is 6), a percentage of $24 \%$ have averages between 7 and 8 and
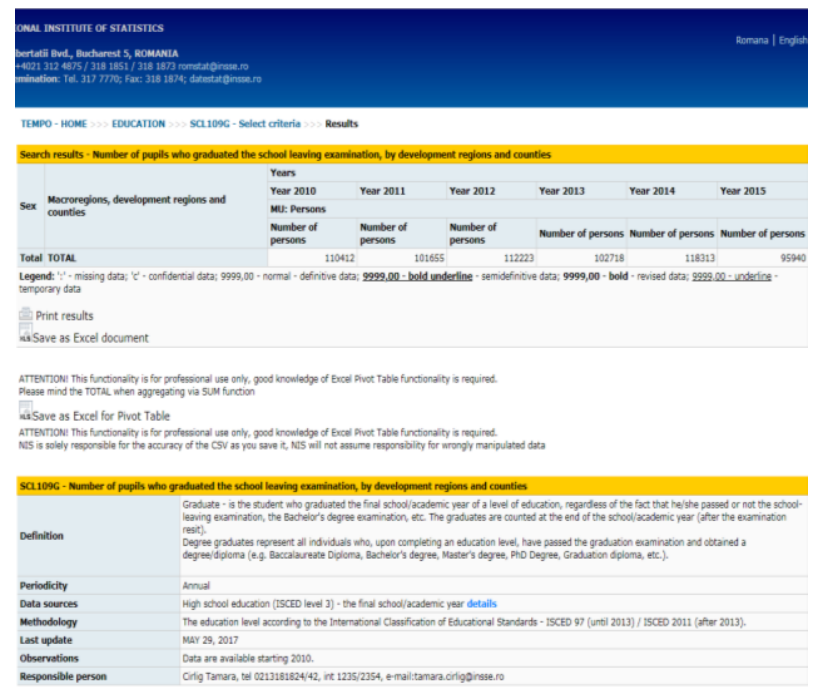

$14 \%$ have averages over 8 .

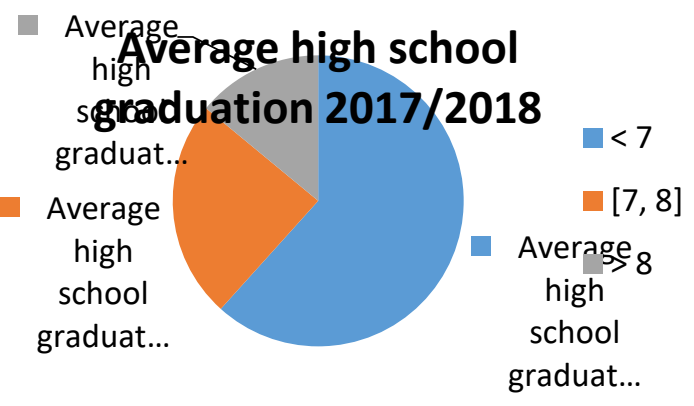

Fig. 2. Number of high school baccalaureate graduates attainment [7]

Fig. 3. Average high school graduation 2017/2018; UPT-Ind. Eng. Domain

\section{Coordinates of the Romanian technical education}

\subsection{Entering in the higher education system}

A part of the higher technical education organizes an admission exam, but at some faculties / specializations, for the students who have passed the baccalaureate admission is done without an exam based on evaluation of knowledge and abilities.

The fact that an admission exam is not organized, and thus high school baccalaureate graduates with poor trainees in basic mathematics and physics become students is a real challenge for both them and teachers.

The teachers, in addition to any other soft skills, must provide students with the minimal knowledge of acquiring the necessary skills to the employment of any engineer, skills that are built day by day through sustained work and on a minimal basis that is supposed to be existent. This can raise a series of questions including: -what skills do these high school students have gained in high school?

- how can the provision of high-level technical skills be strengthened as a basis using a poor background?

- if and under what conditions these students will finish their studies

- how these students will meet the needs of the labor market.

All skills required by students as critical thinking, problem solving, analysing, comparing, extracting information, problem thinking in a certain context, high level skills in the STEM field (Science Technology, Engineering and Math) [3,8] require the ability to see through principles, require the existence of some skills to learn, the existence of a minimal background in fundamental knowledge - in our case - in physics / mathematics / chemistry.

Action and understanding depend on mastered skills and memory. Also, searching, finding, evaluating and communicating information, building knowledge on a particular technical subject matter involves the existence of both cognitive and technical skills and abilities.

How can those who do not have a solid background, do not have learning skills acquired, will learn constructively by building on existing knowledge / information?

\subsection{Challenges in the system}

The learning process involves a constant change / adaptation to the understanding of what surrounds us and learning itself imply that you can see other points of view, understand the differences, etc. When students with a baccalaureate became higher education system students, without the skills to learn, to think of certain problems in a context, learning new things, what can the teachers do? What will be and how is the performance of such students measured? How will those high level knowledge / skills be acquired?

The answer is somewhat simple; teachers have to cope with all the challenges mentioned above. How will they deal? An attempt to respond is "student-centred", "content tailored to students' needs", "new teaching / learning / evaluation methods" and other such well-known texts.

However, good quality teaching cannot fill any gaps that students have. In fact, focusing on a student in the above-mentioned case, the poor students background means also lowering the complexity and volume of the taught content, and the evaluation obviously also undergoes changes. Also, related to this subject, there are at least three problems concerning the teachers:

-the course / lab / seminar should contain an atmosphere favourable to professional development, completion of teacher training;

- the university must prepare its staff for teaching research and future doctoral candidates;

- the poor results of the students have negative repercussions on the teaching staff teaching / evaluation process of the and on the whole image of the university;

Not often, firms employs students in the 4th year bachelor degree, 1 st and 2 nd years at masters, which is 
somewhat positive because the attendance at courses / laboratories / seminars suffers and these future engineers will most often be specialized in a very narrow field.

At the speed of technological advancement and the emergence of new technologies, the world will change rapidly, and what they know to do well-that domain - may disappear. That is why it is very important to develop general knowledge in the field, the ability to absorb and process various knowledge combined with adaptive power to help them in a changing environment.

On the other hand, there is a need to think creatively to stimulate new ways of thinking about teaching / learning / evaluation in order to address some of the problems mentioned above and at the same time to maintain a level of appropriate teaching / learning / assessment goals and mission of higher education.

\subsection{Possible solutions to challenges}

First of all, there is a continuous shift from the terms of education and learning to the training-vocational training. As we know, education is also done outside the school system: family, friends, mass communication, own reading, more recently - the Internet, with deeper effects than those produced within the educational institution.

To improve the learning process, we do not have to look for solutions too much. The learning products to whom are devoted these institutions need only be known to and understood by those who conceive and exploit them.

They are not only well-known but also accepted by the broader view, being integrated into contemporary culture since Seneca's time: "It is a long way of learning, but it is short and effective by exemplifying (to read, practice).

Achieving learning / teaching / evaluation through the use of Information and Communication Technology, open courses are of real importance, but the amount of time needed to prepare them is immense for teachers.

At the same time, the amount of information provided is very high, so processing a large amount of information, learning it for evaluation raises serious difficulties for students. The use of learning materials relies heavily on the visualization aspect, but for the proper assimilation of materials students must still read, think, analyse, compare, and write.

To learn and the learning process itself requires a lot of effort and dedication, that's why it's hard and not everyone can do it successfully.

As possible training methods appropriate to the presented situation - lack of basic knowledge - the training methods, with a great emphasis on the practical side and the permanent emphasis of the theory's presence in practice could be adequate:

-case studies based on real engineering problems [8];integrated laboratories to show the relation between engineering disciplines (e.g. coordinate measurements, assembly, and tolerance allocation)

- using debate as a way of improving the skills of learning, skills of cooperating, and verbal skills, the formation of the technical vocabulary, their expressions and presentation in technical terms. -oral evaluations

Also practice stages are very important. Law no. $258 / 2007$ [9] regarding the practice of school and university students and the Order 3955/09.05.2008 [10] define the persons involved in planning, organizing and supervising the deployment of practice- teaching practice supervisor and tutor - person designated by practice partner that will provide/ensure compliance with their training and acquire professional skills planned for internship by practitioner.

Teaching practice supervisor has to establish an internship program individually tailored to the needs of companies, and consistent with the preparation, personal development opportunities and desires of student/students- the student centred internships.

Because practical training is not a process that looks exclusive the student but one in which he relates to others, is integrated into a team, is subject to rules of the institution where he performs internships, is subject of regulations that exist in its higher education institution and so besides the skills, attitudes and skills acquires improves its skills of teamwork, collaboration, communication so necessary for continuous adaptations to labor market changes and permanent challenges.

The idea of not abandoning classical education - the source of so many discoveries / innovations - and also to not abandon a classical education and a knowledge-based education for a student centred one is more and more common among specialists in education, including our country and even more vocal, from abroad: „Classical education then, in this sense, is a life-long process of applying the "tools of learning" [11, 12]- tools that are skills entailed in basic sciences, engineering basic sciences, and specific of engineering, which travels with the student through her/his career as a professional or as an academic."

In other words, basic skills in learning can be used to learn almost anything at any time and. anywhere. It is worth mentioning that few institutions are as conservative as those of education, especially higher education. The tenacity with which they have defended their "identity" and "autonomy" in society is, however, a merit that cannot be neglected.

But traditionalism has weakened the ability to adapt to new realities and to innovate. The choices (options) are easy and we must take into account both the benefits and the disadvantages.

Emphasizing the economic nature brings knowledge to the firm ground of their utility, but the private economy is often under the sign of immediate benefit.

The acceptance of its character implies the increase of the state's responsibility, but also the danger of bureaucratization, of the statist formalism. Is it possible to find a middle way? Yes, it is but only if we accept a training system such as the public domain, with an emphasis on applications, on professional relevance and on flexible and innovative economic criteria. 


\section{The teacher and the European requirements}

\subsection{What kind of knowledge he has to teach}

Teacher's problem exists and deepens year after year, especially under the contents teached and the quality of the teaching act itself. The causes are many: systemic, selection mode, salary level, conditions for building a career, the speed with which you have to face the many changes imposed by $\mathrm{s}$ the initiated and unfinished reforms, etc.

„Ars longa, vita brevis” - says a very famous Latin proverb. Under the conditions listed, when do you have time to "grow" teachers and valuable researchers? This is the hardest problem and the worst repercussions for the future of technical education. Sociologically, the phenomenon of professional mobility is becoming increasingly widespread, both in the workplace and in the profession itself. The same timeframe may include alternate successive stages of learning, with the actual work steps.

In turn, the need for multidisciplinary strongly asserted in the second half of the last century and the disciplines weakened the rigid separatism that has dominated the world for a long time. Research teams have become multidisciplinary.

The disciplines are established through tradition and law, and the freedom to address the subjects of new areas is reduced, if not excluded. The gap between scientific research and the subjects taught in school has deepened. It is neglected that engineering solves problems. Almost all research issues are multidisciplinary, and researchers need to be trained in the spirit of multidisciplinary. The student is thus relieved of the full deepening of a discipline, of which only a part is useful for his purposes. At least one third of the subject matter of overlapping subjects is saved by using modules. Thus, the modular concept becomes a fundamental element for the interdisciplinary of the sciences and for the continuous process of learning. Apart from the benefits related to efficiency, effort savings, simplification and coherence, one more result emerges: the possibility of individual curriculum. It is a perspective that empowers the individual as the source and the main subject of the training. You cannot go to such a different system overnight, but important steps can be done experimentally in any legal and recognized system. This transition can be accomplished as a slow process. It depends on the maturity of universities and on the resistance of traditionalist disciplines.

\subsection{For whom and with what results are taught}

In the evoked context, at the level of the European Union, as in all developed countries, a decline in the interest of young generations in engineering studies is observed. If demand varies from one country to another, at European level it exceeds the offer.

When the statement "I would like to become a scientist" was analysed, the weight of respondents in the developed countries was very low and the girls had a much higher share than the boys. The answers to the statement "I would like to work in the technical field" were similar. Differences can only be made with regard to the gender of person who responded to this question.

Going forward, it has been argued that not just the interest of young people in the technical field has to be considered, but rather how this topic is treated in school and the perception that young people form in "building" their own identity. To ease this work, teachers should use specially designed materials. It should put more emphasis on technology related to training, practical experience and problem solving in a creative way. At the same time, the examples applied to life events should be more relevant to daily living and much more attractive to boys and girls. Above all, technical training should not be limited to explaining a function.

The need to attract younger generations to technical professions (in particular, engineer) is today, first and foremost, a national problem of the EU Member States, but also a problem of the European Union in its entirety [13]. Technology must, however, be oriented to respond to future problems. For these reasons there is an urgent need for initiatives aimed at ensuring that all those interested in technology also benefit from solid training in the chosen field of activity and those who work in the technical domain to do its best to acquire the knowledge and skills needed to meet the new market demands. The EC consultation has highlighted the importance conferred by industry to Competitiveness competencies. The Expert Group on "New Skills for New Jobs" has clearly demonstrated the importance of coordinating education with industry training to better anticipate future skills demand. Competencies are an essential factor for growth, employment and competitiveness: they are the basis for productivity and innovation. However, Europe faces major challenges related to the supply of skills. Already, the inconsistencies between supply and demand - and in some Member States even lack of skills - are already impeding growth and employment. Investment in training is also investment in innovation, as much of the technical evolution is a consequence of the progressive innovations made by skilled workers and engineers in production units. However, a prerequisite for investing in new skills and training is the need to further develop tools to monitor and anticipate skills needs and inconsistencies. At European level, several instruments are currently being developed for this purpose [14].

\section{Conclusions}

An uninterrupted reform is needed. The need to adapt education becomes so important in the social, economic and scientific environment which changes very fast so that the reform cannot be effective, with discontinuous changes and abrupt rhytm.

Historical experience has shown that the only good reform in education is the one built into the permanent pressure of the system, which takes place in doses required under the sign of continuity. The school must be flexible, highly adaptable. Appropriate legislation, 
transcribed in succinct and sufficiently flexible regulations for adaptation to different ages and continuous changes, is, in this context, a major desideratum.

The authors are not yet able to indicate the path that should be followed, but with certainty, even if only because of the arguments presented in this paper, can say that the current pathway of the Romanian higher education, especially the technical one and within it, especially in the field of industrial engineering, is not a good one.

Therefore, we need to stop, suspend the so-called "reforms" in progress and appeal to the entire community, both university and economic-industrial, for a sincere and detailed analysis of the current situation. Let us look back at the moment when the results were still satisfactory, remember the mistakes that followed to learn from them, show the successes in order to promote them and analyse our needs to design the future paths of action.

At the same time, we affirm with certainty that the recommendations presented in the reports of the European Commission high-level group supporting the modernization of the European higher education match as a "glove" to Romanian technical higher education and to achieve their aim "High quality teaching and learning depends on persons and dedicated institutions supported by policies on teaching and learning. Teachers in higher education must receive the training and support they need to perform their role in excellent conditions " $[1,2]$.

The emphasis placed in Romania on the results of research in higher education is more related to the classification criteria and less to the quality of the educational process. So the finding that many higher education institutions in the EU place too little emphasis on teaching compared to research, even if both are their main missions, is true, as well as the solution proposed by the high European Force by his chairman's statement that this situation needs to be rebalanced and that the role of teaching in defining academic merit needs a stronger accent and recognition.

Last but not least, the importance of knowing the future needs of the economic and industrial society is emphasized. Anticipating employment and skills needs is recognized as having a strategic importance for the success of any enterprise; it influences the competitiveness and long-term prospects of enterprises, irrespective of the industrial sectors in which they are active. In this context, good anticipation and thoroughly prepared restructuring not only can have a positive impact on the sustainable competitiveness of enterprises, but can also generate positive side effects in other markets and sectors, while also improving the overall employability of the workforce and facilitating the transition to new jobs.

\section{References}

1. Communication from the Commission to the European Parliament, the Council, The European Economic And Social Committee and The Committee of The Regions on a renewed EU Agenda for Higher Education, Brussels, 20.09.2011, Available at http://eur-lex.europa.eu/legalcontent/EN/TXT/PDF/?uri=CELEX:52017DC0247\&from $=\mathrm{RO},(2011)$
2. Communication from the Commission to the European Parliament, the Council, the European Economic and Social Committee and the Committee of the Regions Supporting Growth and Jobs - an Agenda for the Modernisation of Europe's Higher Education Systems, Brussels, 30.5.2017 Available at http://eurlex.europa.eu/legal content/EN/TXT/PDF/?uri=CELEX:5 2011DC0567\&rid=13, (2017)

3. Key Challenges for Higher Education in Europe - Annex II: Results of the Public Consultation on the EU's Modernisation Agenda for Higher Education, May (2016)

4. 2018 European Semester: Assessment of progress on structural reforms, prevention and correction of macroeconomic imbalances, and results of in-depth reviews under Regulation (EU) No 1176/2011, (2017)

5. COUNCIL RECOMMENDATION on the 2017 National Reform Programme of Romania and delivering a Council opinion on the 2017 Convergence Programme of Romania

6. Tertiary educational attainment by sex, age group Indicator [t2020_41]; EU Labour Force Survey

7. National Institute of statistics, http://statistici.insse.ro/shop/, last visited April 2018

8. Engineering Education. Research and Development in Curriculum and Instruction, John Heywood, Published by John Wiley \& Sons, Inc., Hoboken, New Jersey, ISBN13978-0-471-74111-4, p. 354, (2005)

9. Law no. 258/19.07.2007 - regarding students practice in Romanian (in Romanian Legea 258/19.07.2007 privind practica elevilor şi studenţilor), MO no. 493/24 July (2007)

10. Order No. 3955/9.05.2008 approving the general framework for internships in undergraduate and master's degree programs organization and the framework agreement on the internship conduct of the in the undergraduate or master's degree programs (in Romanian Ordinul 3955/9.05.2008 privind aprobarea cadrului general de organizare a stagiilor de practică în cadrul programelor de studii universitare de licenţă şi de masterat şi a convenţiei-cadru privind efectuarea stagiului de practică în cadrul programelor de studii universitare de licenţă sau masterat), MO. no. $440 / 12 / 06 / 2008$

11. C. da R. Brito, M. M. Ciampi, et.al. "Engineering Adventure for Youth Generations," in 2016 ASEE Annual Conference \& Exposition Proceedings, (2016)

12. C. R. Brito, M. M. Ciampi, R, et. al Rethinking Engineering Education, 2017 IEEE Frontiers in Education Conference (FIE) Indianapolis, USA, ISBN: 978-1-50904920-2; Available at http://doi.ieecompu tersociety.org/10.1109/FIE.2017.8190506, (2017)

13. G. Mihăiță, Actual issues in Engineering (I) (in Romanian probleme actuale in inginerie (I)), Univers Ingineresc, Year XXIV, Nr. 11 (537) 1-15 June 2013, p. 1, (2013)

14. New Orientations in Community Policies, (in Romanian Noi orientări in politici comunitare) Univers Ingineresc, Year XXIV, Nr. 12 (538) 15-30 June 2013, p. 5, (2013) 